\title{
The Architecture of Illicit Nuclear Trafficking:
}

\section{An Instrumental Approach to Network Analysis}

\author{
Mathilde Le Moal \\ MSc in Global Crime, Justice and Security
}

\begin{abstract}
Since the collapse of the Soviet Union, nuclear trafficking in Russia and the former Soviet Republics has become an ever-prevalent threat for international security. This essay provides an assessment of the organisational structure of this transnational organised crime (TOC). Using the instrumental approach to network analysis and Bourdieu's concept of social and human capital as a methodological framework, this essay investigates the nature of connections maintained among criminals during the various stages of the nuclear trafficking process - acquisition, transportation, sale - and contends that nuclear trafficking displays characteristics both of a stable hierarchy and a fluid network. Thus, it reaches the conclusion that TOC groups involved in this illicit activity present a hybrid form of organisational structure which is best described as a directed network - that is, a criminal entity with a stable group of organisers located at its core, and fluid nodes of individuals in charge of executing the different phases of the trafficking process at its periphery.
\end{abstract}

Keywords: Transnational Organised Crime, Nuclear Trafficking, Social Network Analysis, Social Capital. 


\section{Introduction}

While criminologists have often argued that nuclear theft in Russia and the former Soviet Republic is perpetuated by solitary amateurs, the evidence suggests the presence of a broader trafficking organisation, displaying the involvement of transnational organised crime (TOC) groups. This paper focuses on the organisational structure of nuclear trafficking and assesses whether it can be framed as a stable hierarchy or a fluid network. For this purpose, the first section of this paper reviews the scholarship on the topic of nuclear theft and trafficking and justifies the framing of nuclear trafficking as a TOC. It then continues to provide definitions for 'network' and 'hierarchy', as well as introduce instrumental network analysis combined with Bourdieu's concept of social and human capital as this paper's selected analytical framework. The second section of this paper investigates the organisational characteristics visible at the three different stages of the nuclear trafficking process - acquisition, transportation, sale - through the lens of an instrumental approach to network analysis. It finds that this illicit trade displays features both of a stable hierarchy and a fluid network. Drawing on these findings and using organised crime typologies, it is argued that nuclear trafficking has a hybrid organisational structure, which can be framed as a directed network.

Nonetheless, this essay's conclusion is to be interpreted as a plausible rather than a definitive answer. The academic literature on nuclear trafficking, which is investigated in this paper, largely relies on the data collected by the Database on Nuclear Smuggling, Theft and Orphan Radiation Sources (DTSO). This database comprises only cases of nuclear thefts and smuggling incidents which have been intercepted, offering incomplete information on the subject matter as the phenomenon is likely to be much more frequent than the DTSO suggests. 


\section{Nuclear Trafficking as Transnational Organised Crime}

\subsection{The Emerging Issue of Nuclear Trafficking}

Since the collapse of the Soviet Union, a growing phenomenon of nuclear thefts and attempted smuggling has been witnessed in Russia and the former soviet republics. Considering the risk of nuclear terrorism, the stealing of nuclear material - roughly defined as 'substances containing uranium, plutonium, or thorium' (Morrissey 2005, p. 30) - has been regarded by scholars, policy-makers and organisations such as the International Atomic Energy Agency (IAEA) as a significant international security threat (Mueller 2009). As a matter of fact, allegations of Al-Qaida's interest in the nuclear bomb, as well as previous usage of amateurly fabricated bombs by Chechen rebel groups have led nuclear theft to be placed at the top of the international community's policing agenda (Mueller 2009; Schmid \& Wesley 2006). Nonetheless, an examination of the scholarly literature highlights that the inner workings of nuclear trafficking activities have remained largely unknown both in the political spheres and academia.

Indeed, while conventional wisdom assumes that nuclear thefts occurs mostly in military bases (Zaitseva \& Hand 2003), this criminal activity has largely taken place in the closed nuclear cities of the former Soviet Union (Carpintero-Santamaría 2012; Ouagrham-Gormley 2007). Nuclear cities are guarded facilities devoted to 'the research, development and production [of nuclear materials]', and the maintenance of a nuclear power plant (Carpintero- Santamaría 2012, p. 101). Specifically, the DTSO establishes that nuclear thefts in nuclear cities have mostly been carried out by individuals working within the nuclear complex (Zaitzeva \& Hand 2003). Accordingly, most scholars have framed the issue of nuclear theft in nuclear cities implicitly along the lines of mainstream criminology's economic deprivation theory (Messner \& South 1986), arguing that it results from the 'financial hardships' which nuclear workers have experienced after the collapse of the Soviet Union (Zaitseva \& Hand 2003, p. 824). Essentially, the scholarship has established that economic difficulties have provided them with a rationale for stealing and reselling nuclear materials. Nonetheless, this observation is the point of departure for diverging accounts 
among criminologists on this specific type of criminal activity. Indeed, many of these scholars have deduced that the black nuclear market is driven by desperate nuclear employees who act as solitary amateurs, rather than professional criminal groups (Kupatadze 2010; Oaugrham-Gormley 2007).

Nonetheless, this account is short-sighted and offers 'a poor and incomplete representation of a more sophisticated "invisible" nuclear black market' (Potter \& Sokova 2002, p. 113). While this essay does not negate the assumption that some nuclear thieves are amateurs operating alone, it argues that some others supply nuclear materials to criminal groups, thereby being the first link in a broader trafficking chain. Accordingly, the data of DTSO suggests that nuclear trafficking by criminal groups is an established phenomenon. Between 1991 and 2012, over 630 nuclear smuggling incidents were intercepted in the Black Sea region during their illicit transportation (Zaitseva \& Steinhäusler 2014). Specifically, this essay contends that this criminal activity displays the characteristics of a TOC. The work of Zaitseva (2007) is insightful in this regard, as it argues that between 2001 and 2005, over forty intercepted cases of nuclear trafficking meet the criteria to be framed as the doings of criminal groups. It includes cases where multiple individuals are caught in the process, or when one or more individuals are arrested in possession of this illicit commodity when attempting to cross a border. Arguably, these elements reflect a degree of organisation and premeditation symptomatic of a TOC (Wright 2013). This data also displays the transnational character of this criminal phenomenon, an indispensable criterion for framing a criminal activity as a TOC (Miraglia, Ochoa \& Briscoe 2012). Considering these elements, this paper aims to provide an assessment of the organisational structure and modus operandi of the TOC groups involved in nuclear trafficking. To do so, it uses an instrumental approach to network analysis and Bourdieu's human and social capital concepts as analytical tools, as introduced in the following section. 


\subsection{Definitions and Analytical Framework}

Criminologists have provided the scholarship with a plethora of assessments on the organisational structure of TOC groups, displaying a salient lack of scholarly consensus. This is largely due to the ever-prevalent assumption that TOC groups have moved beyond the mafiaassociated 'hierarchical and pyramidal' type of organisational structure to form looser networks of criminals (Williams 2001, p. 62). Nonetheless, there has been a consistent scholarly debate on what is to be defined as a criminal network (Varese 2010). The concept of network isn't monolithic; it can encompass various forms of organisational structures with features and nuances of their own (Campana 2016). Its holistic character is illustrated in the work of scholars, who use it either as a substantive or instrumental term in their research (ibid.). Implicitly taking a substantive stance, some authors, such as Albini (1971, p. 288) use the word 'network' to describe a specific form of organisational structure and frame criminal networks as 'system[s] of loosely structured relationships functioning primarily because each participant is interested in furthering his own welfare'. Conversely, for scholars following an instrumental approach, the term 'network' is not attached to a specific form of organisation (Campana 2016, p. 3). For instance, using the concept of 'loosely-coupled' and 'tightly-coupled' units, Williams (2001, p. 66) provides a more nuanced definition, simply defining the term 'network' as 'a series of nodes' socially connected. Accordingly, even a hierarchical organisation of roles could be framed as a 'network' formed with tightly-coupled-units, as it displays strong social bonds among participants (Campana 2016; Williams 2001).

Along the lines of Williams' (2001) analysis, this essay uses an instrumental approach and defines 'hierarchy' and 'network' as follows. A fluid TOC network is horizontally-shaped and made of loosely-coupled units (e.g. individuals, solitary cells etc.). In contrast, a stable hierarchical organisation is formed of tightly-coupled units which are vertically organised (e.g. American mafia families in the 1960s). Accordingly, it investigates whether nuclear trafficking is vertically or horizontally organised, composed with tight or loose units of criminals. Hence, this essay identifies the actors involved at each stage of the nuclear trafficking process - acquisition, transport, sale - 
and investigates the nature of the relationships which connect participators at each stage. Specifically, in order to assess the quality of nuclear trafficking participants' social relations, this essay utilizes Bourdieu's (1980) concept of social and human capital. Human capital refers to the specific qualities, technical knowledge and resources possessed by participants involved in the trafficking network, while social capital relates to 'the connections or ties' which exist between them (Bright et al. 2017, p. 425). In turn, this method allows to identify which actors are at the centre or the periphery of the structural organisation of nuclear trafficking. As such, it is assumed that 'high-degree centrality actors possess higher social capital' as they connect the nodes together and organise the network activities. Actors lacking social capital but possessing human capital (i.e. specific and technical knowledge), on the other hand, are framed as operational nodes located at the periphery (ibid.).

The next section uses this framework to categorise nuclear trafficking, showing that the activity is multi-layered and diverse in its organisation.

\section{The Organisational Structure of nuclear trafficking}

\subsection{The Theft of Nuclear Material}

The trafficking of nuclear material shares similar constraints with that of antiquities in that both these illicit commodities are finite resources (Campbell 2013). Contrary to drugs and arms, nuclear materials cannot be illicitly manufactured and can only be accessed in nuclear sites. This specific constraint makes criminal groups involved in nuclear trafficking dependent on access to nuclear sites in order to obtain nuclear material. Furthermore, rather than infiltrating their own members into nuclear facilities, these groups have to establish connections with individuals who are not only able to access this resource, but who also possess the adequate knowledge to identify the nuclear materials to be stolen and to take the necessary precautions for the safe delivery of this radioactive commodity to the next link in the chain. Hence, along the lines of social network analysis (SNA), the actor responsible for the acquisition of these illicit materials is required to have the adequate human capital for this task. This is illustrated in the data collected by the DTSO, 
which demonstrates that most thefts are perpetuated by nuclear workers. In turn, this suggests that bribery is the means through which the connection between nuclear thieves and criminal groups is established ${ }^{1}$.

Specifically, this essay contends that this connection through bribery is enabled by the social capital possessed by criminal groups - that is, their ability to interact socially with individuals outside of their group. Two forms of social capital have been identified as facilitating the supply of nuclear material to criminal groups. The first one is uncovered when examining the work of Shelley (2006), who emphasizes that closed nuclear cities display a significant drug problem. Nuclear trafficking groups assumedly have contacts with local drug dealers, who can connect them with the nuclear workers among their regular clients, so that nuclear traffickers can bribe them to steal nuclear materials. The second form of social capital are the connections that some criminal groups maintain with high-level officials (Lee 2003; Gerber 2000). Corruption in the upperworld indirectly facilitates nuclear theft, as outlined in the case of Yevgeny Adamov, a former Russian minister of Atomic Energy who has been tried for diverting funds allocated to the safeguarding of nuclear facilities to achieve his own private benefit (Schelley 2006). In turn, the lack of security measures in nuclear facilities 'creates an atmosphere in which low-level workers and insiders will be in a position to steal nuclear material' (ibid., p. 554).

It is argued that the role of corrupted high-level officials and nuclear thieves is better understood along the lines of SNA. Indeed, these actors can be described as 'nonredundant contacts' operating in a 'different sphere' from the rest of the criminal group (Williams 2001, p. 85). While these contacts are indispensable for facilitating nuclear trafficking, they are easily replaceable in that they are valuable for their human capital only. This is particularly relevant in the case of nuclear thieves. With drug addictions and economic hardship devastating nuclear cities, criminal groups are provided with a range of nuclear workers possibly willing to help them towards the acquisition of nuclear materials. Similarly, TOC groups can partner with various officials depending on their needs. For instance, the DSTO includes cases of nuclear thefts involving the 
complicity of directors of power plants to that of politicians (Shelley 2006; Zaitseva \& Hand 2003). Hence, these nodes dealing with the supply of nuclear materials to the black market can be framed as fluid and loose ties in the organisational structure of nuclear trafficking criminal groups. Nevertheless, the social capital which is displayed in these groups' capacity to establish connections with the upperworld implies that some of their members have the power to reach and influence these high-level officials; in turn suggesting the presence of high-level criminals and leaders in the nuclear trafficking process.

\subsection{The Transportation of Nuclear Material}

The information collected by the DTSO has enabled scholars to trace an alleged 'nuclear silk road' used by criminal groups (Stone 2001, p. 1632). Accordingly, this illicit commodity is usually transported outside of Russian territory. Most intercepted cases of nuclear smuggling have taken place in the Caucasus region (especially Georgia) and the disputed territories of South Ossetia and Abkhazia (Kupatadze 2007), arguably explained by the fact that many Russian nuclear cities are located along the Russo-Georgian border (Shelley \& Orttung 2006). The DTSO includes many intercepted cases of nuclear material shipping attempts have occurred in Georgian seaports (Zaitseva \& Steinhäusler 2014). It also records numerous arrests of nuclear sellers in Turkey (Schmid \& Spencer-Smith 2012). Hence, the available data suggests that Georgia and Turkey are respectively significant transit and destination countries (Nelson, Roslycky \& Ouagrham-Gormley 2007). Accordingly, the tracing of this cross-border smuggling route suggests 'levels of sophistication in cross-border smuggling operations' (Lee 2006, p. 28), as it requires that groups involved in nuclear trafficking have 'experience in avoiding detection, knowledge of safe routes, protection by corrupt authorities' (Zaitseva \& Hand 2003, p. 830).

Examining the work of Lee (2006), who conducted interviews with Western customs officials, suggests that the social capital of these TOC groups is a decisive factor for the successful transportation of this illicit commodity. This scholar finds that different groups involved in nuclear trafficking are able to cooperate and communicate together; they 'collect and share information on 
which Russian customs posts are equipped with radiation monitors' and choose their routes accordingly (ibid., p. 28). Additionally, their social capital is visible in their ability to bribe highlevel officials and directors of border and maritime customs posts in Georgia (Kupadtaze 2007; Shelley \& Orttung 2006). In contrast, most individuals who have been caught in the transportation process are not professional criminals. Rather, cases reported in the DTSO suggest that transporters of nuclear materials are 'unaware couriers' individuals paid by criminal groups to transport illicit materials without necessarily knowing what they are trafficking (Kupatadze 2007, p. 47; Shelley \& Orttung 2006; Williams \& Woessner 2000). As for nuclear thieves, couriers are likely 'individuals desperate to support their families' recruited along the Russo-Georgian border, an area suffering from 'extreme poverty' levels (Shelley \& Orttung 2006, p. 22).

Hence, the organisational structure of the transportation stage is rather complex. While it exposes the participation of unaware and amateurish couriers, it also shows the use of sophisticated means to enable the successful transportation of nuclear materials to its destination - cooperation among criminal groups, bribery of officials. This paper argues that the couriers are a looselyconnected node in the organisational structure of nuclear trafficking. Indeed, transporters share similarities with nuclear thieves. Not only are couriers motivated by economic deprivation, but they also do not possess valuable social capital. This is reflected in the lack of information that they are given about the merchandise that they transport, which also implies that they have limited social connections with the criminal groups that employ them. Additionally, the multiple arrests of couriers in the Caucasian region suggests that criminal groups must change transporters regularly, which makes this node significantly fluid. Nonetheless, the transportation phase also displays characteristics of a stable and vertically-organised structure. The ability of nuclear trafficking groups to cooperate or bribe high-level officials implies that specific members possess significant social capital, which arguably makes them more important and stable than others. Additionally, the delegation of the task of transportation in itself as well as the pre-selection of the smuggling route on strategic grounds suggests the existence of a higher chain of command. 


\subsection{The Sale of Nuclear Material}

While the data of the DTSO suggests that Turkey is a 'preferred destination' for trafficked nuclear material (Lawlor 2011, p. 75), it provides limited information on potential buyers (Schmid $\&$ Spencer-Smith 2012). Most intercepted transaction cases involve nuclear sellers who were either unable to reach for the alleged buyer or were arrested during sting operations conducted by Turkish policemen pretending to be potential buyers (ibid.). Nonetheless, the DTSO provides broad insights on the nature of some arrangements between criminal groups and these buyers. For instance, the database includes a case which occurred in the nuclear city of Chelyabinsk, Russia, in 1998, where a large quantity of uranium had been stolen, 'almost enough for a nuclear bomb' (Lee 2006, p. 27). While no suspect was apprehended, the scale of this operation suggests that nuclear trafficking groups had established arrangements with potential buyers prior to the acquisition of this nuclear material. When examining the transaction phase specifically, intercepted cases in Turkey provide insights on the actors involved in this stage. They suggest that the use of intermediaries is the means through which transactions are operated. For instance, a case involved an individual who was arrested after attempting to sell uranium in Ankara, Turkey. There, he was supposed to meet the buyer, as he had been instructed to by a contact (Zatiseva \& Steinhäusler 2014). Another case displaying the role of intermediaries occurred in 2006, when police officers conducted a sting operation. While the sellers were supposed to attend, they sent instead an intermediary with a sample of the nuclear material (Lawlor 2011).

The transaction phase displays a similar level of complexity as that of the previous stages. These intercepted cases demonstrate that - as for nuclear thieves and transporters - intermediaries possess minimal social capital, maintain limited contacts with actors involved in the trafficking process other than to receive instructions, and are not involved in the arrangements made with potential buyers prior to the transaction meeting. Specifically, the 'sting ring' case suggests that the use of intermediaries is a method for protecting members of the nuclear trafficking group who had previously established contact with the buyer. In the event of a sting operation, it is the courier who is apprehended. The use of intermediaries as covers also suggests that they are easily 
replaceable actors. Overall, these elements enable the categorization of middlemen as loose and fluid nodes in the organisational structure of nuclear trafficking. Conversely, the transaction stage also displays hierarchical characteristics. The fact that some members are protected using intermediaries implies that they hold important positions in the organisational structure of nuclear trafficking operations. The sting operation case described above suggests that these specific individuals are indispensable due to their social capital for finding and establishing connections with potential buyers. Additionally, their role in enhancing and directing the nuclear trafficking process is further displayed in their ability to make arrangements with buyers before they acquire the nuclear material. Hence, these are stable actors located within the organisational core of the criminal group. As a matter of fact, the characteristics of the organisational structure for the transaction phase are consistent with that of the acquisition and transportation phases. It includes organisational elements both of a fluid network and a stable hierarchy.

Nuclear trafficking displays a hybrid form of organisational structure. Along the lines of these findings and after examination of Williams (2001, p. 69) and Le's (2012, p. 127) organised crime typologies, this essay argues that nuclear trafficking's organisational structure can be framed as a 'directed network'. A directed network is composed of a core group of organisers and a peripheral network of associates and contacts acting under the direction and supervision of the organisers. Each phase of the nuclear trafficking process displays these characteristics. They involve loose and fluid nodes of 'field workers', actors who oversee the execution of the trafficking process, such as nuclear thieves, couriers and intermediaries. They are recruited and receive instructions from a core and stable group of individuals in charge of enabling and directing the illicit operation as a whole. Specifically, organisers use their social capital to establish connections with local drug dealers, other trafficking groups, high-level officials, and potential buyers to plan and enable the successful operation of the trafficking process.

Building on this insight, this essay argues that these findings have implications for the criminologist scholarship as well as for the policing of nuclear trafficking. Firstly, the instrumental 
approach to network analysis and Bourdieu's human and social capital concepts provide valuable tools for investigating the organisational structure of TOC groups. As it does not assume 'any structure a priori' (Campana 2016, p. 1), this method enables scholars to uncover complex structures that cannot be categorized as definite stable hierarchies and fluid networks. Additionally, while the downstream use of a typology was possible in the case of nuclear trafficking, typologies might not consistently grasp the complexity of other organised crime structure. Hence, while the substantial interpretation of the term 'network' has become an everprevalent paradigm in the criminologist literature (Borgatti \& Foster 2003), this essay suggests that criminologists should seek a more neutral approach to investigate organised crime structures through the use of instrumental network analysis as their preferred method. Secondly, as outlined in Le's (2012) work, identifying the organisational structure of a criminal group is indispensable to effectively disrupt its activities. As such, it can be derived from this assumption that the policing of nuclear trafficking should be adapted to tackle the hybrid structure of nuclear trafficking organisations and should, accordingly, focus on targeting the actors at their core to effectively eliminate the threat they pose to international security.

\section{Conclusion}

This essay has analysed the organisational structure of nuclear trafficking through the lens of an instrumental network analysis and Bourdieu's concept of social and human capital. Through investigating the various stages of this mode of TOC, this essay has found that groups engaged in nuclear trafficking organise differently across multiple stages of activity. While some nodes of actors are rather fluid and loose, others are stable, and located at the core of the nuclear trafficking process, planning and directing of its operations. This core group of actors possess extensive social capital, which enables them to recruit a network of replaceable participators to establish connections with outsiders such as; local drug dealers, high-level officials, other trafficking groups, and to find buyers for trafficking nuclear material. In turn, this essay concludes that the organisational structure of nuclear trafficking can be framed as a directed network. This conclusion 
challenges the dominant network paradigm and suggests that an instrumental network analysis is a more appropriate framework when investigating organised crime structures.

\section{Notes}

1. As outlined in the introduction, this paper's findings are to be understood as a plausible rather than a definite answer. As such, while it hasn't been discussed in academic research, it remains possible that TOC groups involved in nuclear trafficking also threaten or blackmail nuclear workers in order to obtain nuclear materials.

\section{References}

Albini, JL 1971, The American Mafia: Genesis of a Legend, Appleton Century Crofts, New York.

Borgatti, SP \& Foster, PC 2003, 'The network paradigm in organizational research: A review and typology', Journal of management vol. 29, no. 6, pp. 991-1013, DOI 10.1016/S01492063_03_00087-4.

Bourdieu, P 1980, 'Le capital social: Notes Provisoires' [Social Capital: Preliminary Notes], Actes de la Recherche en Sciences Sociales, vol. 31, no. 1, pp. 2-3, viewed 16 August 2020, $<$ https://www.persee.fr/doc/arss_0335-5322_1980_num_31_1_2069>.

Bright, D, Greenhill, C, Britz, T, Ritter, A \& Morselli, C 2017, 'Criminal network vulnerabilities and adaptations', Global Crime, vol. 18, no. 4, pp. 424-441, DOI 10.1080/17440572.2017.1377614.

Campana, P 2016, 'Explaining criminal networks: Strategies and potential pitfalls' Methodological Innovations, vol. 9, pp. 1-10, DOI 10.1177/2059799115622748.

Campbell, PB 2013, 'The illicit antiquities trade as a transnational criminal network: Characterizing and anticipating trafficking of cultural heritage', International Journal of Cultural Property, vol. 20, no. 2, pp. 113-154, DOI 10.1017/S0940739113000015.

Carpintero-Santamaría, N 2012, 'The incidence of illegal nuclear trafficking in proliferation and international security', Behavioral Sciences of Terrorism and Political Aggression, vol. 4, no. 2, pp. 99-109, DOI 10.1080/19434472.2010.512156.

Gerber, J 2000, 'On the Relationship between Organized and White-Collar Crime: Government, Business, and Criminal Enterprise in Post-Communist Russia', European Journal of Crime Criminal Law and Criminal Justice, vol. 8, no. 4, pp. 327-342, DOI 10.1163/15718170020519229. 
Kupatadze, A 2010, 'Organized Crime and the trafficking of radiological materials: The case of Georgia', The Nonproliferation Review, vol. 17, no. 2, pp. 219-234, DOI 10.1080/10736700.2010.485425.

Kupatadze, A 2007, 'Radiological Smuggling and Uncontrolled Territories: The Case Of Georgia', Global Crime, vol. 8, no. 1, pp. 40-57, DOI 10.1080/17440570601121852.

Lawlor, Maj. Gen. B 2011, 'The Black Sea: Center of the nuclear black market', Bulletin of the Atomic Scientists, vol. 67, no. 6, pp. 73-80, DOI 10.1177/0096340211426506.

Le, V 2012, 'Organised crime typologies: structure, activities and conditions', International Journal of Criminology and Sociology, vol. 1, pp. 121-131, viewed 16 August 2020, $<$ http://www.ncjrs.gov/App/publications/abstract.aspx?ID $=267256>$.

Lee, R 2003, 'Nuclear smuggling: patterns and responses', Parameters: Unted States Army War College Quarterly, vol. 33, no. 1, pp. 95-111, viewed 16 August 2020, $<$ https://www.hsdl.org/?view\&did=1868>.

Lee, R 2006, 'Nuclear smuggling, rogue states and terrorists', China and Eurasia Forum Quarterly, vol. 4, no. 2, pp. 25-32, viewed 16 August 2020, $<$ https://isdp.eu/content/uploads/images/stories/isdp-main-pdf/2006 lee_nuclearsmuggling-rogue-states-and-terrorists.pdf $>$.

Messner, SF \& South SJ 1986, 'Economic deprivation, opportunity structure, and robbery victimization: Intra- and interracial patterns', Social Forces, vol. 64, no. 4, pp. 975-991, DOI 10.1093/sf/64.4.975.

Miraglia, P, Ochoa, R \& Briscoe, I 2012, 'Transnational Organised Crime and Fragile States', OECD Development Co-operation Working Papers 5, pp. 4-29, viewed 16 August 2020, $<$ https://gsdrc.org/document-library/transnational-organised-crime-and-fragile-states/>.

Morrissey, S 2005, 'IAEA Reports Increase in Nuclear Trafficking', Arms Control Today, vol. 35, no. 9 , p. 30 , viewed 16 August 2020, <https://link-galecom.ezproxy.is.ed.ac.uk/apps/doc/A139587007/ITOF?u=ed_itw\&sid=ITOF\&xid=9b0cf6 c4>.

Mueller, J 2009, Atomic obsession: nuclear alarmism from Hiroshima to al-Qaeda, Oxford University Press, Oxford.

Nelson, DN, Roslycky, LL, \& Ouagrham-Gormley, SB 2007 'Terrorists, Trafficking, and WMD Still the Greatest Danger/Sonia Ben Ouagrham-Gormley Responds', Arms Control Today, vol. 37, no. 8, p. 55, viewed 16 August 2020, <https://www-jstororg.ezproxy.is.ed.ac.uk/stable/23628259>.

Ouagrham-Gormley, SB 2007, 'An Unrealized Nexus? WMD-related Trafficking, Terrorism, and Organized Crime in the Former Soviet Union', Arms Control Today, vol. 37, no. 6, pp. 613, viewed $16 \quad$ August 2020, $<\underline{\text { https://www-jstor- }}$ org.ezproxy.is.ed.ac.uk/stable/23628165>. 
Potter, WC \& Sokova, E 2002, 'Illicit nuclear trafficking in the NIS: What's new? What's true?', The Nonproliferation Review, vol. 9, no. 2, pp. 112-120, DOI 10.1080/10736700208436896.

Schmid, A \& Wesley, R 2006, 'Possible Causes and Motives of Nuclear and Radiological Terrorism in the Light of Empirical Data on Smuggling Incidents of Nuclear Materials' in J Victoroff (ed.) Tangled Roots: Social and Psychological Factors in the Genesis of Terrorism. IOS Press, Amsterdam, pp. 357-398.

Schmid, A \& Spencer-Smith, C 2012, '1llicit Radiological and Nuclear Trafficking, Smuggling and Security Incidents in the Black Sea Region since the Fall of the Iron Curtain-an Open Source Inventory', Perspectives on Terrorism, vol. 6, no. 2, pp. 117-157, viewed 16 August 2020, <https://www.universiteitleiden.nl/binaries/content/assets/governance-and-globalaffairs/isga/perspectives-on-terrorism/2012-2.pdf $>$.

Shelley, LI 2006, 'Trafficking in Nuclear Materials: Criminals and Terrorists', Global Crime, vol. 7, no. 3-4, pp. 544-560, DOI 10.1080/17440570601073335.

Shelley, LI \& Orttung, R 2006, 'Criminal acts: How organized crime is a nuclear smuggler's new best friend', Bulletin of the Atomic Scientists, vol. 62, no. 5, pp. 22-23, DOI 10.2968/062005007.

Stone, R 2001, 'Nuclear trafficking: 'A real and dangerous threat', Science, vol. 292, no. 5522, pp. 1632-1636, DOI 10.1126/science.292.5522.1632.

Varese, F 2010, 'What is organised crime?' in F Varese (ed.) Organized Crime: Critical Concepts in Criminology. Routledge, London, pp. 1-33.

Williams, P 2001, 'Transnational criminal networks' in J Arquilla \& D Ronfeldt. (eds) Networks and netwars: the future of terror, crime, and militancy. RAND Corporation, Santa Monica, Arlington, Pittsburgh, pp. 61-99.

Williams, P \& Woessner, PN 2000, 'Gangs go nuclear', World Today, vol. 56, no. 12, pp. 7-9, viewed 16 August 2020, <https://www-jstor-org.ezproxy.is.ed.ac.uk/stable/40476456>.

Wright, A 2013, 'Mapping rough terrain: the contested concept of organised crime' in A Wright (ed.) Organised Crime. Routledge, London, New York, pp. 1-21.

Zaitseva, L 2007, 'Organized Crime, Terrorism and Nuclear Trafficking', Strategic Insights, vol. 6, no. 5, pp. 1-18, viewed 16 August 2020, $<$ http://hdl.handle.net/10945/11473>.

Zaitseva, L \& Steinhäusler, F 2014, 'Nuclear Trafficking Issues in the Black Sea Region', EU Non-Proliferation Papers, no. 39, pp. 1-24, viewed 16 August 2020, $<$ https://www.files.ethz.ch/isn/187240/April_2014_39.pdf $>$.

Zaitseva, L \& Hand, K 2003, 'Nuclear smuggling chains: Suppliers, intermediaries, and endusers', American Behavioral Scientist, vol. 46, no. 6, pp. 822-844, DOI $10.1177 / 0002764202239177$. 
Vol. 1 September 2020 pp. 43-58

DOI https://doi.org/10.2218/ccj.v1.4942 